\title{
Near-Wall Flame and Flow Measurements in an Optically Accessible SI Engine
}

\author{
Marius Schmidt $^{1}$ (D) Carl-Philipp Ding ${ }^{1} \cdot$ Brian Peterson $^{2}$ (D) Andreas Dreizler ${ }^{1}$ (D) \\ Benjamin Böhm ${ }^{1}$ (D)
}

Received: 4 December 2019 / Accepted: 15 April 2020 / Published online: 14 May 2020

(c) The Author(s) 2020

\begin{abstract}
Near-wall processes in internal combustion engines strongly affect heat transfer and pollutant emissions. With continuously improving capabilities to model near-wall processes, the demand for corresponding measurements increases. To obtain an in-depth understanding of the near-wall processes within spark-ignition engines, flame distributions and flow fields were measured simultaneously near the piston surface of an optically accessible engine operating with homogeneous, stoichiometric isooctane-air mixtures. The engine was operated at two engine speeds ( $800 \mathrm{rpm}$ and $1500 \mathrm{rpm}$ ) and two different intake pressures (0.95 bar and 0.4 bar). Flame distributions were obtained at high spatial resolution using high-speed planar laser induced fluorescence of sulfur dioxide $\left(\mathrm{SO}_{2}\right)$. Particle tracking velocimetry was utilized to measure the flow field above the piston at high spatial resolution, which enabled the determination of hydrodynamic boundary layer profiles. Flame contours were extracted and statistical distributions of the burnt gas area determined. The burnt gas distributions were compared with the simultaneously recorded high-speed flow field measurements in the unburnt gas. A direct comparison with motored engine operation showed comparable boundary layer profiles until the flame approaches the wall. Flow acceleration due to flame expansion rapidly increases velocity gradients and the boundary layer development becomes highly transient. The interaction of flame and flow depends on the operating conditions, which results in a different evolution of burnt gas positions within the field-of-view. This has additional implications on the development of the velocity boundary layer. Depending on the operating conditions, the flame strongly affects the velocity boundary layer profiles resulting in boundary layer thicknesses (defined by $50 \%$ maximum velocity) in the order of $80-180 \mu \mathrm{m}$.
\end{abstract}

Keywords Near-wall reacting flows - Internal combustion engines · Boundary layer flows · Particle tracking velocimetry $(\mathrm{PTV}) \cdot$ Planar laser induced fluorescence (PLIF)

Marius Schmidt

schmidt@ rsm.tu-darmstadt.de

1 Department of Mechanical Engineering, Reactive Flows and Diagnostics, Technical University of Darmstadt, Otto-Berndt-Str. 3, 64287 Darmstadt, Germany

2 School of Engineering, Institute for Multiscale Thermofluids, University of Edinburgh, The King's Building, Mayfield Road, Edinburgh EH9 3BF, UK 


\section{Introduction}

The near-wall reacting flow within internal combustion (IC) engines play an imperative role in the design of cleaner, more efficient engine technologies. Modern IC engines are designed with lower cylinder volumes and higher power densities to achieve appreciable gains in fuel efficiency (i.e. lower $\mathrm{CO}_{2}$ emissions) and are intended as compatible powertrains within hybrid-electric vehicles. These downsized, boosted engine concepts, however, are subject to increased heat losses at chamber surfaces, which will considerably affect engine efficiency and pollutant emissions (e.g. unburnt hydrocarbons and $\mathrm{CO}$ formation) (Alkidas 1999). In spark-ignition (SI) engines, gas phase convection is regarded as the primary mechanism of near-wall heat transfer (Heywood 1988; Han and Reitz 1997). This heat transfer is largely governed by the mass and energy transfer processes occurring within the boundary layer adjacent to chamber surfaces.

In engines, the energy transport in boundary layers is not well understood. In particular, the wall-bounded flow is unsteady and the outer fluid is not constant in pressure, temperature or velocity. Consequently, the boundary layer is not spatially uniform or fully developed; it quickly deviates from established theory (Schlichting and Gersten 2017). IC engine simulations based on Reynolds Average Navier Stokes (RANS) simulations and Large Eddy Simulations (LES) utilize wall models and empirical formulas to predict the energy transfer at chamber surfaces (Rutland 2011; Borman and Nishiwaki 1987; Rakopoulos et al. 2010; Han and Reitz 1997). Most wall models are based on established theory (e.g. law-of-the-wall, originally developed for steady channel flows (Schlichting and Gersten 2017)). Recent experimental and Direct Numerical Simulations (DNS) studies report strong deviations of engine boundary layers compared to the law-of-the-wall (Jainski et al. 2013; MacDonald et al. 2017; Renaud et al. 2018; Schmitt et al. 2016). Most empirical formulas are based on heat flux measurements associated with individual engines and operating conditions (Borman and Nishiwaki 1987; Rakopoulos et al. 2010). While empirical formulas can yield agreeable findings with measurements performed within a single engine, most formulas are not universal and do not provide accurate findings at different operating conditions or for different engine platforms. The inability to predict energy transfer at chamber surfaces rivals the ability to predict the motored engine pressure trace accurately. This, in turn, is critical as the pressure trace defines the thermodynamic environment, which must be predicted accurately in order to effectively simulate other processes such as injection, ignition, flame development, heat release and exhaust emissions.

Experimental measurements resolving the governing processes within boundary layers are required to improve our understanding of energy transfer processes at engine surfaces and to provide valuable data for wall model development. As convection plays a dominant role near surfaces in SI engines, many researchers have focused on hydrodynamic boundary layer measurements. Several studies have employed Laser Doppler Anemometry (LDA) to resolve gas velocities near engine surfaces (Hall et al. 1986; Foster and Witze 1987; Pierce et al. 1992). While such measurements have provided relevant trends of the ensemble-average hydrodynamic boundary layer structure, LDA measurements are only capable of providing a single, localized velocity vector per measurement. This makes it challenging to understand relevant flow-field behavior that influences the boundary layer structure. In comparison to conventional particle image velocimetry (PIV) approaches, hybrid PIV and particle tracking velocimetry (PTV) techniques are better suited to resolve flow gradients (Kähler et al. 2012). Hybrid PIV/ PTV and micro PIV techniques have significantly advanced the ability to measure 
near-wall flow fields and study boundary layer flows within engines (Alharbi and Sick 2010; Jainski et al. 2013; MacDonald et al. 2017; Renaud et al. 2018; Shimura et al. 2019; Ding et al. 2019). Investigations utilizing PIV/PTV techniques have revealed several sub-millimeter vortices moving through the outer boundary layer in engines and have shown discrepancies of the engine boundary layer compared with the law-ofthe-wall. For example, previous investigations have shown velocity profiles exhibiting a viscous sublayer region, but no evidence of a logarithmic layer (Jainski et al. 2013; MacDonald et al. 2017). Similar deviations from the law-of-the-wall have also been reported in recent DNS studies of an engine-like flow (Schmitt et al. 2016). Based on such findings, MacDonald et al. (2017) hypothesized that the turbulence in the boundary layer depends on the balance between the turbulence generated by wall-shear and the core flow. Shimura et al. (2019) performed PTV measurements in an engine above the piston and found a closer resemblance to the laminar Blasius solution than to the law-of-the-wall. However, this particular finding was found to be crank-angle (CA) dependent. The non-stationary flow, the pressure gradient due to compression, and the influence of the tumble flow were given as reasons for this dependency. These aforementioned findings have greatly contributed towards the development of more predictive wall models for RANS and LES-based simulations (e.g. Ma et al. 2017).

While previous investigations provide an improved understanding to boundary layer flow in engines, they have been limited to non-reacting flow conditions. Ding et al. (2019) recently performed PIV/PTV measurements above a piston in an optically accessible engine to resolve the transient near-wall flow development associated with an approaching flame front. Their measurements revealed unburnt gas flow acceleration ahead of the flame as the flame approached the piston surface. This flow acceleration, accredited to flame expansion, rapidly increased the velocity gradients at the wall, and decreased the unburnt gas boundary layer thickness. Measurements revealed stark contrast to the non-reacting boundary layer, which did not exhibit strong transient flow behavior. Moreover, their measurements showed a strong interdependency between the near-wall velocity magnitude and flame development, which apparently influenced subsequent combustion. In particular, near-wall velocity magnitude, controlled in part by localized flow outside of the boundary layer, played a contributing factor to boundary layer behavior and near-wall flame development. This analysis reveals the need to study boundary layer flow and flame development for significant differences in the incylinder flow features (e.g. tumble flow).

This work investigates the influence of the flame on the evolution of the boundary layer flow for different operating conditions that produce global differences of the incylinder tumble flow motion. The flame and near-wall flow are measured simultaneously above the piston surface of an optically accessible SI engine by means of PIV/ PTV and planar laser induced fluorescence (PLIF) of sulfur dioxide $\left(\mathrm{SO}_{2}\right)$. Measurements are performed at $\mathrm{kHz}$ repetition rates to resolve the near-wall flow field and flame distribution at near-CA resolution. These measurements are complemented by PIV measurements in a larger field of view to characterize the global tumble motion with respect to the operating condition. The operating conditions focus on variations combinations of engine speed $(800 \mathrm{rpm}$ and $1500 \mathrm{rpm})$ and intake pressures $(0.4 \mathrm{bar}$ and 0.95 bar), for which boundary layer flows in the same engine under motored operation were recently reported (Renaud et al. 2018). The present work focuses mainly on the analysis of phase-averaged data. A complementary investigation of instantaneous phenomena is subject to future studies. 


\section{Experimental Setup}

\subsection{Engine and Operating Conditions}

Measurements were performed in a single-cylinder spray-guided direct-injection sparkignition (SG-DISI) optical engine. The engine is equipped with a 4-valve pentroof cylinder head, centrally mounted spark plug, and centrally mounted injector. Optical access is provided through a quartz-glass cylinder and a flat piston window. The engine has a bore and stroke of $86 \mathrm{~mm}$ and a geometric compression ratio of 8.7. The engine is embedded in a test rig facility that allows controlled and repeatable operating conditions. Further details of the engine and test rig are described in Baum et al. (2014) and Freudenhammer et al. (2015).

The engine was operated with port fuel injection of stoichiometric isooctane-air mixtures. Fuel injection took place $1.4 \mathrm{~m}$ upstream of the engine to provide homogeneous fuel-air mixtures into the engine. Four operating conditions were investigated as summarized in Table 1. This included a variation of engine speed ( $800 \mathrm{rpm}$ and $1500 \mathrm{rpm}$ ) and intake pressure ( 0.4 bar and 0.95 bar). The spark timing was adjusted for each operating condition to have a maximum in-cylinder pressure at about $9^{\circ} \mathrm{CA}$ (crank-angle degrees) aTDC (after compression top dead center). The measurements presented in this manuscript coincide with a comprehensive velocimetry and reacting flow database for this optical engine (Baum et al. 2014; Zentgraf et al. 2016; Peterson et al. 2019), which includes recent investigations of engine boundary layer flows (Ding et al. 2019; Renaud et al. 2018).

\subsection{High-Resolution Flame and Flow Diagnostics}

Figure 1 shows the experimental setup for the simultaneous flame and flow measurements. For flame imaging, PLIF of the inert tracer $\mathrm{SO}_{2}$ was used. The fluorescence of $\mathrm{SO}_{2}$ has been proven to be a good flame marker since it increases with the local gas temperature (Honza et al. 2017). High-speed $\mathrm{SO}_{2}$-LIF is preferable to OH-LIF, especially at elevated pressures, because the pulse energy of high-speed dye lasers is still limited and results in a low signal-to-noise ratio. A frequency-quadrupled Nd:YAG laser (Edgewave, INNOSLAB) excited $\mathrm{SO}_{2}$ with a repetition rate of $8.2 \mathrm{kHz}$ and energy of $0.36 \mathrm{~mJ} /$ pulse. The laser light

Table 1 Engine operating conditions

\begin{tabular}{lllll}
\hline Operating conditions & A & B & C & D \\
\hline Engine speed (rpm) & 800 & 800 & 1500 & 1500 \\
Avg. intake pressure (bar) & 0.95 & 0.40 & 0.95 & 0.40 \\
Avg. intake temp. (K) & 311 & 314 & 303 & 310 \\
Spark timing $\left({ }^{\circ} \mathrm{CA}\right.$ aTDC) & -14.2 & -22.2 & -22.2 & -27.2 \\
IMEP (bar) & 5.7 & 1.9 & 6.2 & 2.1 \\
CoV (bar) & 1.2 & 2.2 & 1.5 & 2.4 \\
$P_{\text {max }}$ (bar) & 31.5 & 9.9 & 33.9 & 12.7 \\
$P_{\text {max }}\left({ }^{\circ} \mathrm{CA}\right.$ aTDC) & 9.4 & 14.5 & 8.7 & 8.2 \\
Laminar flame thickness at $-5^{\circ} \mathrm{CA}(\mu \mathrm{m})$ & 45 & 159 & 39 & 108 \\
Laminar flame speed at $-5^{\circ} \mathrm{CA}\left(\mathrm{ms}^{-1}\right)$ & 0.56 & 0.34 & 0.53 & 0.47 \\
$T_{a d}(\mathrm{~K})$ & 2431 & 2146 & 2434 & 2247 \\
\hline
\end{tabular}




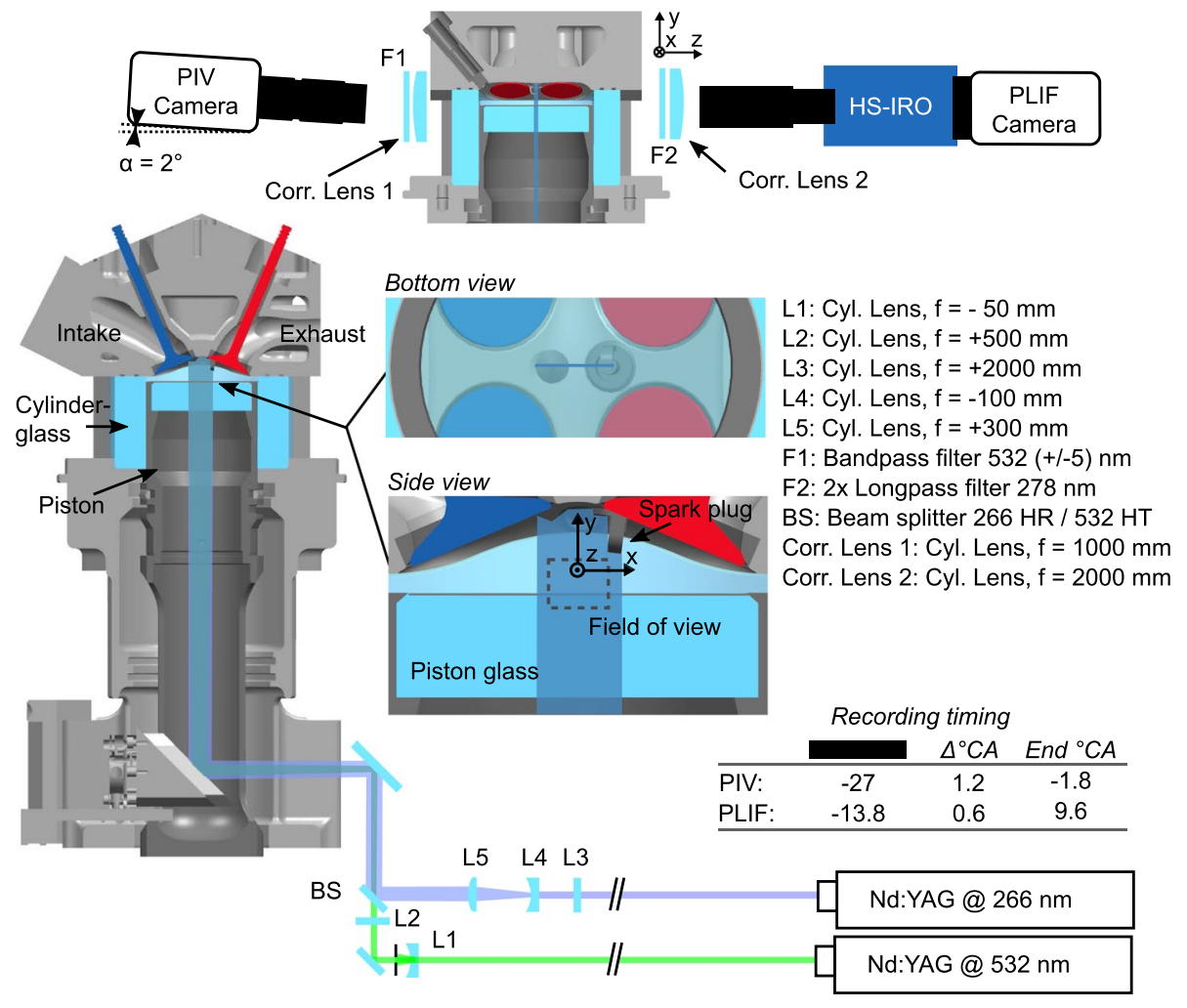

Fig. 1 Experimental setup

was formed into a sheet (15 mm width, $180 \mu \mathrm{m}$ FWHM thickness) and vertically guided into the engine through a Bowditch piston. The fluorescence signal was detected in the tumble symmetry plane using an image intensifier (HS-IRO, LaVision) with $100 \mathrm{~ns}$ exposure to suppress flame luminosity. A CMOS camera (Phantom v711, Vision Research) recorded the intensified signals. The intensifier was equipped with a $150 \mathrm{~mm}$ lens (Halle, $\mathrm{f} / \#=2.5$ ) and $145 \mathrm{~mm}$ extension rings providing a magnification of $\mathrm{M}=1.6$ (80.6 pxl/ $\mathrm{mm})$. A corrective lens was used to correct optical aberrations induced by the cylinder glass. The optical resolution $(101 \mu \mathrm{m})$ was determined using a Siemens star target. The PLIF system recorded a $12 \times 9 \mathrm{~mm}^{2}$ field-of-view (FOV) near the piston surface. The FOV was slightly offset from the cylinder axis towards the spark plug where the flame can be studied during its early development phase. The reader is referred to Peterson et al. (2015, 2019) for further information of the early flame kernel development in other regions of the cylinder within this engine.

The flow field was measured in the central symmetry plane using a hybrid PIV/PTV technique. Silicone oil droplets (DOWSIL 510, Dow Corning; $0.5 \mu \mathrm{m}$ diameter) were seeded into the intake air. The particle response time was estimated to be $0.42 \mu$ s for the in-cylinder conditions after ignition (Tropea et al. 2007). This is negligible compared to the laser pulse separation of $d t=8 \mu \mathrm{s}$ and the time scales of the flow (Kolmogorov time scale $t_{\eta}=80 \mu \mathrm{s}$ to $200 \mu \mathrm{s}$, estimated using the vorticity field of motored operation (Ding 2018, p. 120) aquired by high-resolution PTV (Renaud et al. 2018)). The particles were illuminated 
with a frequency-doubled Nd:YAG laser (Edgewave, INNOSLAB). A laser sheet was formed (20 mm width, $60 \mu \mathrm{m}$ FWHM thickness) overlapping the same path as the UV laser and guided into the engine. Mie-scattering was detected using a CMOS camera (Phantom v711, Vision Research) equipped with a $180 \mathrm{~mm}$ macro lens (Sigma, f/\# = 8) and $45 \mathrm{~mm}$ extension rings. The camera was slightly tilted vertically to reduce vignetting at the piston. A corrective lens was used to reduce optical aberrations due to astigmatism. The magnification was $M=1.9(95 \mathrm{pxl} / \mathrm{mm})$.

All cameras and lasers were synchronized to the crank shaft with a timing unit (HSCv2, LaVision). For a given recording, five work/rest sequences (250 fired and 350 motored (non-fired) cycles for $800 \mathrm{rpm}, 250 / 875$ for $1500 \mathrm{rpm}$ ) were performed and measurements were recorded for the last 100 fired cycles of this sequence. For each operating condition, two runs were recorded, resulting in 200 recorded cycles. One recording of operating condition $\mathrm{D}$ had too low seeding densities and was discarded, resulting in 100 cycles for case D. For $800 \mathrm{rpm}$, flow field images were recorded from -27 to $-1.8^{\circ} \mathrm{CA}$ every $1.2^{\circ} \mathrm{CA}$ $(4.1 \mathrm{kHz})$, and PLIF images were acquired from -13.8 to $9.6^{\circ} \mathrm{CA}$ every $0.6^{\circ} \mathrm{CA}(8.2 \mathrm{kHz})$. For $1500 \mathrm{rpm}$, the image recording rate was decreased to $2.4^{\circ} \mathrm{CA}$ for the flow measurements and to $1.2^{\circ} \mathrm{CA}$ for flame imaging.

\subsection{Data Processing}

Images of a spatially defined target (LaVision) within the engine were used to calibrate PLIF and PTV images using a 3rd order polynomial fit to match viewing planes of each system. PLIF images were processed in MATLAB. Background correction was applied using the signal of three non-fired cycles aquired directly after the fired measurements. The $\mathrm{SO}_{2}$ signal is insensitive to the observed temperature changes in the unburnt gas region (Honza et al. 2017) and increases by a factor of 2 to 5 from the unburnt to the burned gas region. A sheet correction was performed when the flame filled the FOV. A $13 \times 13$ pxl $(161 \mu \mathrm{m})$ moving median filter was applied to the flame images. Images were then binarized with local, adaptive thresholds determined within a moving $50 \times 50$ pxl window. The local probability of burnt gas (referred to as "flame PDF") was calculated from binary images that identified the burnt gas at fixed CAs.

High resolution flow-field measurements were calculated using Davis 8.4 .0 with a hybrid PIV/PTV algorithm (Stanislas et al. 2005). Image pre-processing included a moving background subtraction and particle intensity normalization ( $9 \mathrm{pxl}$ window size). PIV vectors were calculated with decreasing window size (64-32 pxl), 75\% overlap, and adaptive interrogation window shape. Vectors with correlation values below 0.1 were removed. PTV was calculated for a particle size range of 2-5 pxl and a correlation window size of 8 pxl. The same vector post-processing was applied as for the PIV steps. A denoising filter was applied using a polynomial fit of 2 nd order. Binarized flame images were used to mask the location of the flame in PTV images. For some images, the 3D propagating flame caused significant beam steering of the Mie scattering signal, causing particle images to become defocused. These regions were identified using a local standard deviation filter. Vectors at positions where the local standard deviation was low (indicating a weak particle signal) were removed. The piston position was determined for each recorded CA using phase-averaged images from which the peak intensity location was determined. PTV vectors are mapped onto a regular mesh to present flow-field statistics at a resolution superior to PIV. The average vector distance in the images was $110 \mu \mathrm{m}$. Velocity vectors were 
spatially averaged onto a Cartesian mesh with $\Delta x / \Delta y=1 \mathrm{~mm} / 0.05 \mathrm{~mm}$, providing more than two vector per cell for each cycle.

\subsection{Global Flow Field}

The global flow field was acquired with $5^{\circ} \mathrm{CA}$ resolution in the tumble plane using a PIV approach. The setup utilized a similar high-speed Nd:YAG laser setup as described for the high-resolution measurements, formed into a light sheet of $800 \mu \mathrm{m}$ thickness $(13.5 \%$ max. intensity). A high-speed CMOS camera (SA-X2, Photron) equipped with a Sigma lens (105 mm F2.8 Macro, f/\# = 11) captured the image pairs with varying, optimized time separation $(3.5-49 \mu \mathrm{s})$. The same silicone oil as in the high-resolution measurements was used, though no correction lens was needed for this magnification $(\mathrm{M}=3.1,15.9 \mathrm{pxl} /$ $\mathrm{mm}$ ). Calculation of the cross-correlation was also done in DaVis 8.4.0 with decreasing window size (two passes at $64 \times 64$ pxl with $50 \%$ overlap; two passes at $32 \times 32$ pxl with $75 \%$ overlap). A peak ratio threshold of 1.3 and a universal outlier median filter removed false vectors.

\section{Results}

\subsection{Instantaneous Flame Images}

Figure 2 shows PLIF images as the flame approaches the piston surface to discuss differences of the flame structure near the piston for each operating condition. For flame imaging, the high speed $\mathrm{SO}_{2}$-PLIF measurements were used such that the bright fluorescence signal corresponds to the burnt gas region. The piston surface is highlighted by the gray line and the spark plug is located at the top right corner. The selected images represent the typical flame structure/behavior observed at each operational condition. Each column shows two consecutively acquired images for each of the four investigated operating conditions (cases A-D). The time duration between the images corresponds to the temporal

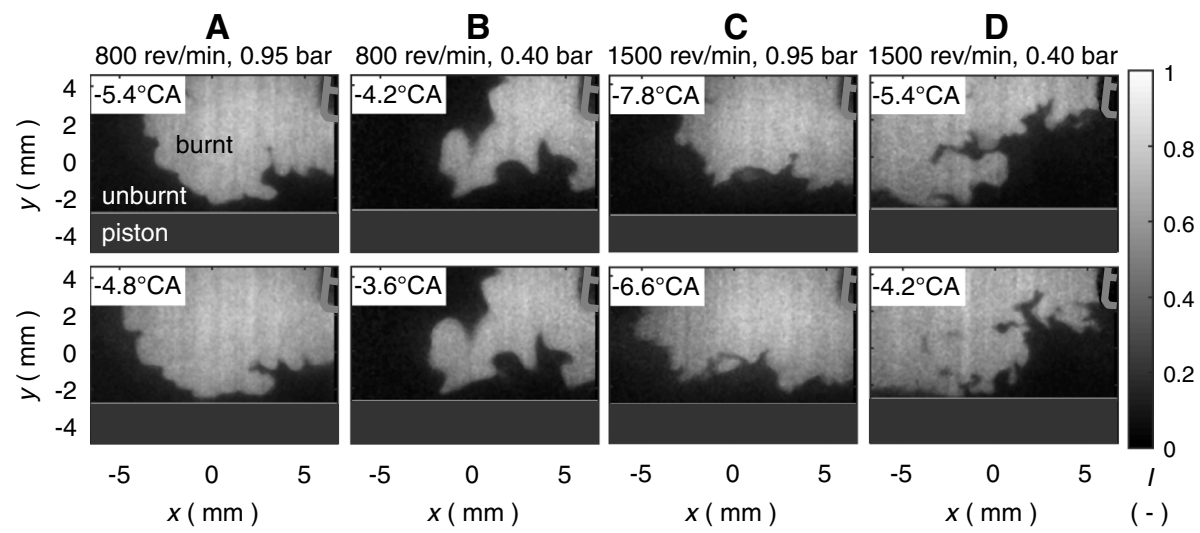

Fig. 2 Instantaneous PLIF images of the flame for all four operating conditions (columns) for two time steps of individual cycles (rows) 
resolution of the flame measurements: $0.6^{\circ} \mathrm{CA} / 125 \mu \mathrm{s}$ for $\mathrm{A}$ and $\mathrm{B} ; 1.2^{\circ} \mathrm{CA} / 133 \mu \mathrm{s}$ for $\mathrm{C}$ and D.

The flame wrinkling scales depicted in Fig. 2 differ significantly depending on the thermodynamic in-cylinder conditions and the turbulent flow field. For case B with the lowest intake pressure and turbulence level, flame structures with larger scale wrinkling in comparison to other cases are observed and are spatially well-resolved. Flame structures can easily be followed from one image to the other. The higher intake pressure of 0.95 bar (case A) results in finer wrinkling and correspondingly the flame curvature changes from positive to negative values on much smaller scales along the flame contour. At the same time, the flame propagates faster and flame structures are more difficult to track from one frame to the next. As the engine speed increases to $1500 \mathrm{rpm}$, the flame wrinkles become finer and flame wrinkling increases. Little difference can be observed between case $\mathrm{C}$ and D. For these conditions, the finest wrinkling scales are not well-resolved compared to cases $\mathrm{A}$ and $\mathrm{B}$.

\subsection{Burnt Gas Position}

Figure 3 shows the evolution of the flame as it approaches the piston surface by the local probability of burnt gas given by the color map at four selected CAs for all four operating conditions (cases A-D). White indicates regions where burnt gas is less than $10 \%$ of the recorded cycles and yellow represents more than $90 \%$. To discuss the evolution of the flame, individual CAs were selected for each operating condition to achieve a similar flame

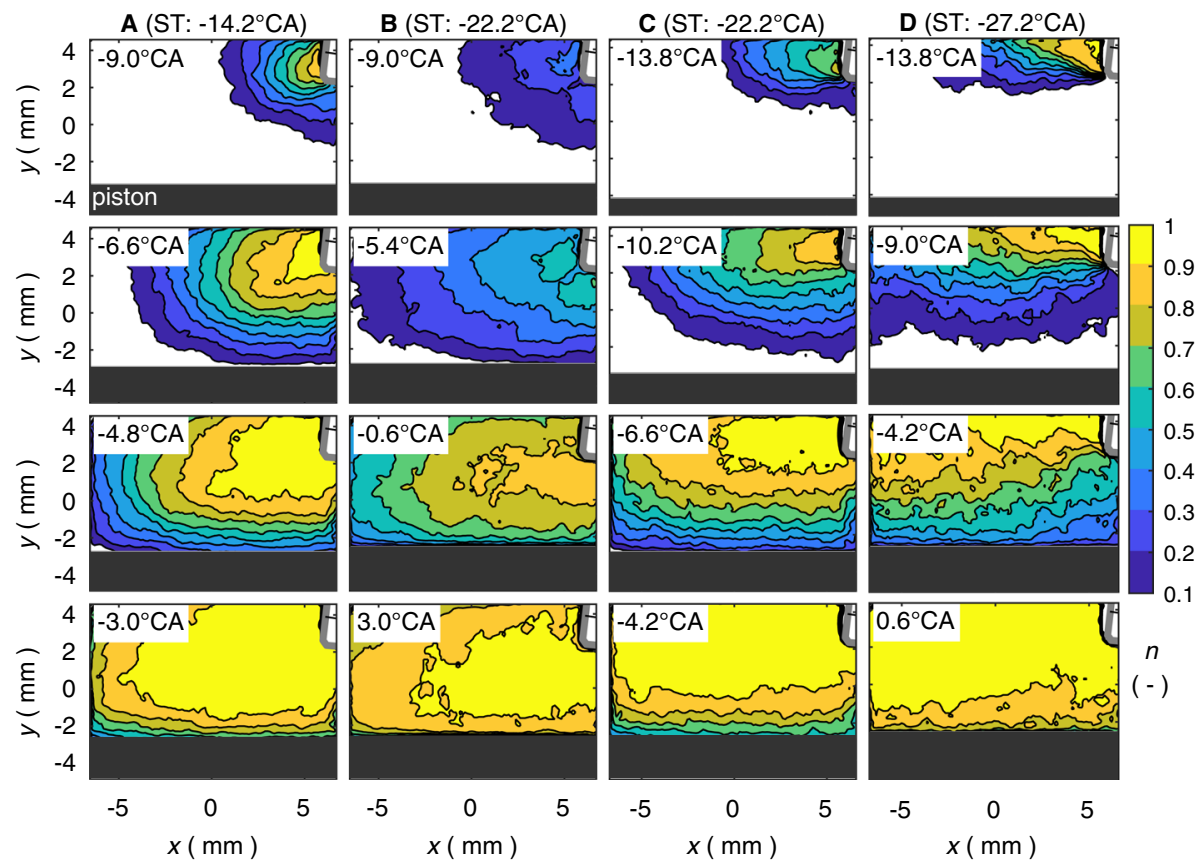

Fig. 3 Flame PDFs showing the burnt gas distributions at selected CAs (rows) for cases A-D (columns) 
PDF within each row of Fig. 3. This was necessary due to the varying flame propagation speeds of the four investigated operating conditions.

For operating conditions $\mathrm{A}, \mathrm{B}$, and $\mathrm{C}$, the flame propagates on average from top right (from the spark plug) to the bottom left. The iso-contours of the PDFs are oval shaped and centered around the spark plug (row 1 and 2). For case B, the flame propagates slower than for case A due to the lower gas density and higher residual gas level associated with the lower intake pressure ( $>20 \%$ of the in-cylinder mass in comparison to $<10 \%$ for the higher load cases). The flame position exhibits larger cycle-to-cycle fluctuations for case $\mathrm{B}$ than case $\mathrm{A}$, which result in a wider distance between individual iso-contour levels and lower peak values of $n$ within the FOV; up to $n<0.6$ for case B and $n>0.9$ for case A. However, for the higher engine speed, the spatial extent of the flame PDF levels within the FOV do not show such a large difference as observed for A and B despite the same difference in the intake pressure. In the second row, the level of $n>0.1$ has a similar size (yet a different shape on the left side) and for both cases high values are reached close to the spark plug. This similarity continues for the subsequent CAs. While the spatial extent of the flame PDF is similar, flame propagation is still slower for case D than C.

Once the flame approaches the piston, the iso-contours start to align parallel to the piston surface. The flame is constrained by the upward moving piston, which results in a narrowing of the iso-contour lines. At this timing the cylinder pressure starts to rise beyond the pressure in motored engine operation (not shown). The flame is still in the stage of the early flame development when less than $5 \%$ of the mixture is consumed, typically regarded as the crucial stage of flame development that defines subsequent combustion (Peterson et al. 2014). When the flame approaches the piston, the flame propagates preferentially straight towards the piston for case $\mathrm{A}-\mathrm{C}$, while flame propagation has a trend from left to right for case D. The flow field is responsible for the flame propagation direction and is discussed in the following sections.

\subsection{Global Flow Field}

The tumble flow still present at ignition is strongly governed by the characteristics of the intake flow. Figure 4 depicts the phase-averaged global flow field in the tumble plane of all four operating conditions at selected CAs during compression. The color map gives the normalized velocity magnitude and the streamlines indicate the flow direction. Velocity normalization was conducted using the average piston speed (A and B (800 rpm): $2.29 \mathrm{~ms}^{-1}$; $\mathrm{C}$ and D $\left.(1500 \mathrm{rpm}): 4.30 \mathrm{~ms}^{-1}\right)$. It is apparent, that the tumble is not centered in the combustion chamber, but is offset from the cylinder axis towards the positive $\mathrm{x}$-direction as shown in Fig. 4. The normalized velocity fields are very similar for A and $\mathrm{C}$, with comparable magnitudes and a good agreement of the tumble position. Towards top dead center, velocity magnitudes decrease, the tumble is compressed between the rising piston and the cylinder head, and the tumble center moves further in the positive X-direction. Lowering the engine load in case B weakens the tumble, which increases the area of low velocity around the tumble center. However, late in the compression, at $-60^{\circ} \mathrm{CA}$ and $-30^{\circ} \mathrm{CA}$, the overall structure of the flow fields tend to align for case A, B and C. At $-60^{\circ} \mathrm{CA}$ case $\mathrm{A}, \mathrm{B}$, and $\mathrm{C}$ show a region of high velocity magnitudes induced by the piston motion above the surface of the piston in addition to high magnitudes near the cylinder head. The clockwise vortex structure of the tumble flow is apparent.

In contrast, the high engine speed and low engine load case D exhibits a more pronounced tumble flow. For example, the low velocity region indicating the tumble center 


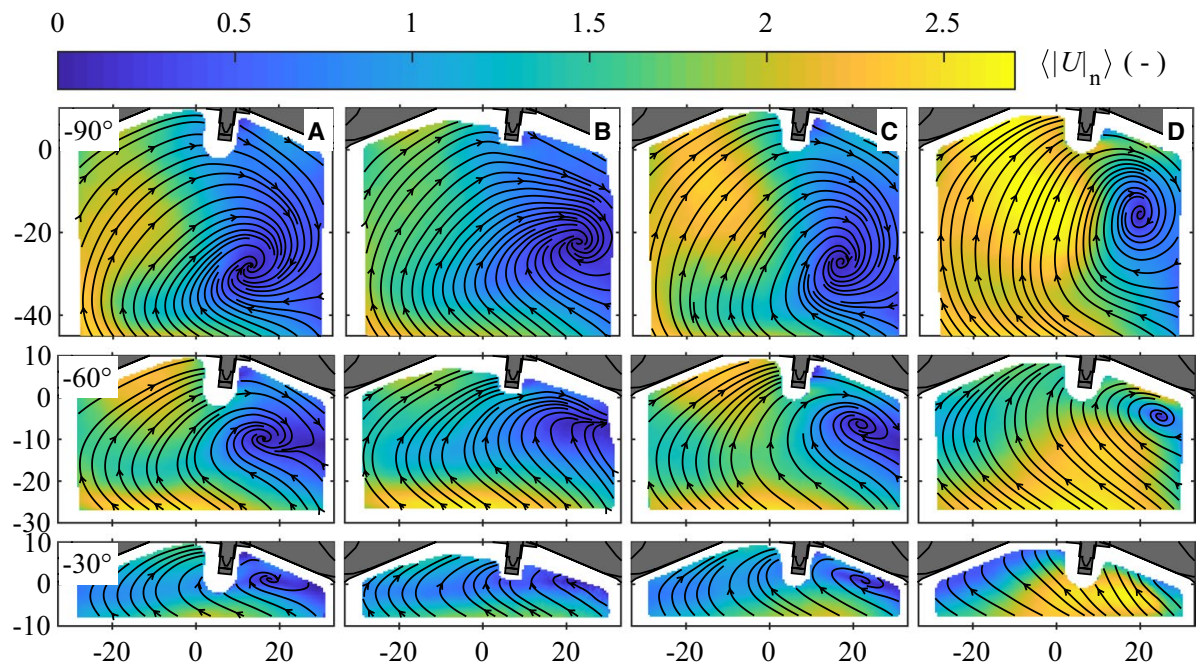

Fig. 4 Phase-averaged flow fields (296 cycles) for all four operating conditions (columns) at selected CAs during compression. Normalization velocity $v_{\text {piston, } \mathrm{A}, \mathrm{B}}=2.29 \mathrm{~ms}^{-1} ; v_{\text {piston, }, \mathrm{D}}=4.30 \mathrm{~ms}^{-1}$. Geometric dimensions in $\mathrm{mm}$

is small and well defined compared to the other cases, which exhibit a larger low velocity region. The tumble center is located higher and farther to the right for each CA. At $-90^{\circ} \mathrm{CA}$ it features a vertical oval shape next to a region of high magnitudes pointing more vertically than in case $\mathrm{A}, \mathrm{B}$, and $\mathrm{C}$. This continues at $-60^{\circ} \mathrm{CA}$, where the vertical contraction of the cylinder volume results in a more circular tumble shape. Above the piston surface, the magnitude is significantly higher for all shown CAs. Furthermore, streamlines in this area are positioned closer towards the top-left corner of the FOV, since the tumble center is located closer to the cylinder head than in the three other cases.

As mentioned, this difference in the flow field can be attributed to variations in the momentum of the intake flow. In operating conditions with part load, a backflow from the cylinder into the intake pipe occurs, which induces additional high frequency pressure oscillations in the intake gas column. These pressure oscillations cause fluctuations of the intake jets' magnitude and direction over the valves. In the lower engine speed case B, these fluctuations are less significant and appear more evenly distributed over the intake phase. In case D, however, these oscillations result in a strong overshoot of the intake velocity, thus energizing the tumble motion and creating a stronger vortex throughout the rest of the cycle (Welch et al. 2020). A more detailed analysis of this phenomena is outside the scope of this paper and subject of future work.

After examining the global flow evolution, the impact of these characteristics on the near-wall flow and its interaction with the flame is discussed in the next section.

\subsection{Near-Wall Flow Field}

Figure 5 shows high-resolution phase-averaged flow fields of all four operating conditions at selected CAs. Velocity vectors are available as long as particles have not evaporated due to the flame, which represents a slight bias for regions of high flame probability at later 

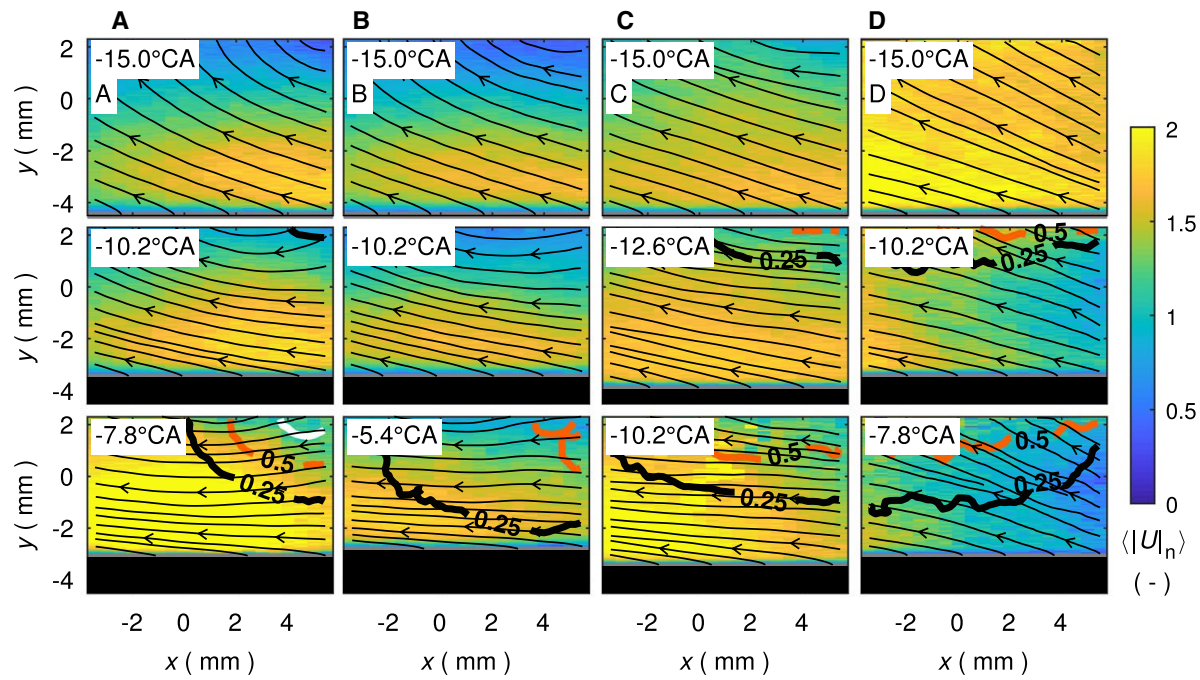

Fig. 5 Phase-averaged flow fields and flame PDFs for all four operational conditions (columns) at selected CAs after ignition. Normalization velocity $v_{\text {piston, A,B }}=2.29 \mathrm{~ms}^{-1} ; v_{\text {piston,C,D }}=4.30 \mathrm{~ms}^{-1}$

crank angles. At $-15^{\circ} \mathrm{CA}$, the near-wall flow fields of operating conditions $\mathrm{A}$ to $\mathrm{C}$ are very similar to the corresponding near-wall flow fields for motored engine operation which were presented in Renaud et al. (2018). The flow is directed in the negative x-direction with decreasing flow magnitudes towards the top. Following the tumble flow, in this location the streamlines of the average flow field curve upwards. In instantaneous flow fields this region exhibits cross-flow-like structures (not shown). Operating condition D has a different flow field with higher overall magnitudes and a significantly less pronounced decrease of the velocity magnitudes at the top of the FOV, which agrees with the trend discussed for the global flow field.

The motored flow field measurements in Renaud et al. (2018) have shown that the velocity magnitude decreases towards top dead center during late compression. The deceleration was found to be stronger for cases A, B, and C than for D. For fired operation, this flow development is altered by the propagating flame. To investigate the influence of the flame on the flow field, the $25 \%, 50 \%$ and $75 \%$ iso-contours of the flame PDFs (as shown in Fig. 3) are overlaid on the flow fields in Fig. 5. For case A, the flow between the piston surface and the flame front is accelerated significantly. The flame propagates from the top right to the bottom left. The gas expansion within the flame causes an acceleration of the flow in front of the flame. For case B, flow acceleration is much weaker, which agrees with the slower flame propagation. The flow acceleration in front of the flame for case $\mathrm{C}$ is similar to case A. The fluctuations of unburnt gas positions are smaller compared to B and a significant acceleration of the flow downstream of the flame can be observed. In contrast, case D is again very different from the other operating conditions. With increasing CA, the flow opposes the flame on the right side of the FOV and the flow near the flame decelerates. Consequently, the overall velocity magnitudes are reduced. This is in contrast to the motored flow fields, where the flow field of case D has the smallest deceleration compared to the others (Renaud et al. 2018). It should be emphasized that the observed phenomena are of a local nature and are not necessarily representative for the complete combustion chamber. It is very likely 
that for all cases a flow acceleration or deceleration in front of the flame can be found depending on the location within the cylinder. Since the analysis of these phenomena is naturally limited to the measurements conducted within the study, these aspects are intended as the focus of future investigations. Nevertheless, the different characteristics of the operating conditions reveal different flame-flow-wall interaction scenarios.

In Fig. 6, normalized velocity profiles of the phase-averaged horizontal velocity component $U_{\mathrm{x}, \mathrm{n}}$ are shown to compare the evolution of the flow within the near-wall region. The velocity profiles are extracted at $x=0 \mathrm{~mm}$ and are referenced to the piston position $y_{\text {piston }}$. The velocities were averaged in local windows of $1 \mathrm{~mm}$ in the x-direction and $50 \mu \mathrm{m}$ in the $\mathrm{y}$-direction. In this manner, a high spatial resolution orthogonal to the piston was achieved while keeping the number of velocity data sufficiently high. Results are shown for every $50 \mu \mathrm{m}$ with the first point being $25 \mu \mathrm{m}$ from the piston surface. Values are linearly interpolated in-between. The error bars shown for every 6th measurement point represent the $95 \%$ confidence interval of the mean estimate. Due to the reduced number of cycles for case $\mathrm{D}$, the confidence intervals are significantly larger compared to the other operating conditions. The previously described flow evolution can be observed in Fig. 6; the flow accelerates for cases A to $\mathrm{C}$ and decelerates for case D.

To investigate the development of the velocity boundary layer, locations at which the flow reaches $50 \%$ of the maximum velocity $\left(\delta_{50}\right)$ are highlighted in Fig. 6 with crosses. This metric was used, since the common definition of the boundary layer thickness $\delta_{99}$ is sensitive to fluctuations in the bulk flow. The maximum velocity was extracted after applying a moving Gaussian filter with a width of $250 \mu \mathrm{m}$ similar to that done in Renaud et al. (2018). The velocities at $\delta_{50}$ are determined using a linear interpolation between the neighboring results. Highly resolved measurements of the motored flow in Renaud et al. (2018) have shown that the velocities at $\delta_{50}$ are very close or equal within the region where the velocity profile is linear. The velocity gradients calculated from $\delta_{50}$ and the corresponding velocities are thus assumed to be close to the wall gradient, although it should be emphasized that the measurement resolution is not sufficient to resolve and confirm this directly. Values of $\delta_{50}$ range from 80 to $180 \mu \mathrm{m}$, where the thinnest boundary layers are observed for case $\mathrm{C}$ and the thickest for case $\mathrm{B}$.

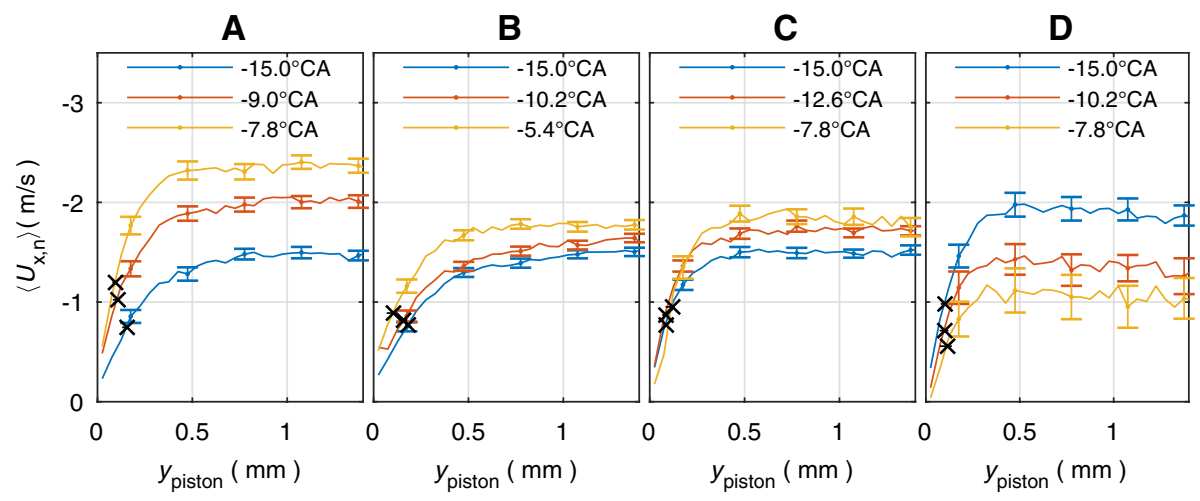

Fig. 6 Phase-averaged velocity boundary layer profiles for cases A to D. Vertical bars indicate 95\%-confidence intervals of every 6th data point. Crosses denote the position at which the flow reaches $50 \%$ of the maximum velocity $\left(\delta_{50}\right)$ 


\section{Conclusions}

Simultaneous flame and flow field measurements were carried out near the piston surface of an optically accessible IC engine in fired operation using laser induced fluorescence of $\mathrm{SO}_{2}$ and particle tracking velocimetry. The engine was operated with premixed stoichiometric isooctane-air mixtures. Four operational conditions including two engine speeds, $800 \mathrm{rpm}$ and $1500 \mathrm{rpm}$, and two intake pressures, 0.4 bar and 0.95 bar, were investigated. For three operational conditions flame propagation was similar within the field-of-view in terms of the flame growth direction and the flame PDF was aligned parallel to the piston when the flame approached the piston surface. For $1500 \mathrm{rpm}$ and 0.4 bar intake pressure a different global flow field evolution with a stronger tumble leads to changes in the flame propagation and the near-wall flow field.The flame was inclined with respect to the piston when the flame approached the piston surface. For fired engine operation, the boundary layer flow strongly deviated from motored engine conditions. The near-wall flow was accelerated or decelerated depending on the orientation of the flame towards the flow. This significantly affected the boundary layer development. Flow acceleration rapidly increased while flow deceleration decreased velocity gradients near the wall. This interaction of the flame and flow close to the wall shows that the impact of the flame needs to be considered in boundary layer modeling to correctly predict heat losses. Future studies will make use of the simultaneous high-speed data acquired, which e.g. allows for instantaneous and conditioned analysis of the flame and flow interaction.

Acknowledgements Open Access funding provided by Projekt DEAL. We kindly acknowledge generous support by Deutsche Forschungsgemeinschaft through SFB-Transregio 150 Project Number 237267381TRR150 and the European Research Council (Grant \#759546). A. Dreizler is grateful for the generous support by the Gottfried Wilhelm Leibniz program.

\section{Compliance with Ethical Standard}

Conflict of interest The authors declare that they have no conflict of interest.

Open Access This article is licensed under a Creative Commons Attribution 4.0 International License, which permits use, sharing, adaptation, distribution and reproduction in any medium or format, as long as you give appropriate credit to the original author(s) and the source, provide a link to the Creative Commons licence, and indicate if changes were made. The images or other third party material in this article are included in the article's Creative Commons licence, unless indicated otherwise in a credit line to the material. If material is not included in the article's Creative Commons licence and your intended use is not permitted by statutory regulation or exceeds the permitted use, you will need to obtain permission directly from the copyright holder. To view a copy of this licence, visit http://creativecommons.org/licenses/by/4.0/.

\section{References}

Alharbi, A.Y., Sick, V.: Investigation of boundary layers in internal combustion engines using a hybrid algorithm of high speed micro-PIV and PTV. Exp. Fluids 49(4), 949-959 (2010). https://doi. org/10.1007/s00348-010-0870-8

Alkidas, A.C.: Combustion-chamber crevices: the major source of engine-out hydrocarbon emissions under fully warmed conditions. Prog. Energy Combust. Sci. 25(3), 253-273 (1999). https://doi. org/10.1016/S0360-1285(98)00026-4 
Baum, E., Peterson, B., Böhm, B., Dreizler, A.: On the validation of les applied to internal combustion engine flows: part 1: comprehensive experimental database. Flow Turbul. Combus. 92(1-2), 269-297 (2014). https://doi.org/10.1007/s10494-013-9468-6

Borman, G., Nishiwaki, K.: Internal-combustion engine heat transfer. Prog. Energy Combust. Sci. 13(1), 1-46 (1987). https://doi.org/10.1016/0360-1285(87)90005-0

Ding, C.P.: Wandnahe Interaktion von Strömung und Flamme in einem Ottomotor. Books on Demand, Norderstedt (2018)

Ding, C.P., Peterson, B., Schmidt, M., Dreizler, A., Böhm, B.: Flame/flow dynamics at the piston surface of an ic engine measured by high-speed PLIF and PTV. Proc. Combust. Inst. 37(4), 4973-4981 (2019). https://doi.org/10.1016/j.proci.2018.06.215

Foster, D.E., Witze, P.O.: Velocity measurements in the wall boundary layer of a spark-ignited research engine. In: SAE Technical Paper Series, SAE Technical Paper Series. SAE International400 Commonwealth Drive, Warrendale, PA, USA (1987). https://doi.org/10.4271/872105

Freudenhammer, D., Peterson, B., Ding, C.P., Boehm, B., Grundmann, S.: The influence of cylinder head geometry variations on the volumetric intake flow captured by magnetic resonance velocimetry. SAE Int. J. Eng. 8(4), 1826-1836 (2015). https://doi.org/10.4271/2015-01-1697

Hall, M.J., Bracco, F.V., Santavicca, D.A.: Cycle-resolved velocity and turbulence measurements in an IC engine with combustion. In: SAE Technical Paper Series, SAE Technical Paper Series. SAE International400 Commonwealth Drive, Warrendale, PA, USA (1986). https://doi. org/10.4271/860320

Han, Z., Reitz, R.D.: A temperature wall function formulation for variable-density turbulent flows with application to engine convective heat transfer modeling. Int. J. Heat Mass Transf. 40(3), 613-625 (1997). https://doi.org/10.1016/0017-9310(96)00117-2

Heywood, J.B.: Internal Combustion Engine Fundamentals. McGraw-Hill Series in Mechanical Engineering. McGraw-Hill, New York (1988)

Honza, R., Ding, C.P., Dreizler, A., Böhm, B.: Flame imaging using planar laser induced fluorescence of sulfur dioxide. Appl. Phys. B 123(9), 1 (2017). https://doi.org/10.1007/s00340-017-6823-7

Jainski, C., Lu, L., Dreizler, A., Sick, V.: High-speed micro particle image velocimetry studies of boundary-layer flows in a direct-injection engine. Int. J. Eng. Res. 14(3), 247-259 (2013). https://doi. org/10.1177/1468087412455746

Kähler, C.J., Scharnowski, S., Cierpka, C.: On the uncertainty of digital PIV and PTV near walls. Exp. Fluids 52(6), 1641-1656 (2012). https://doi.org/10.1007/s00348-012-1307-3

Ma, P.C., Ewan, T., Jainski, C., Lu, L., Dreizler, A., Sick, V., Ihme, M.: Development and analysis of wall models for internal combustion engine simulations using high-speed micro-piv measurements. Flow Turbul. Combust. 98(1), 283-309 (2017). https://doi.org/10.1007/s10494-016-9734-5

MacDonald, J.R., Fajardo, C.M., Greene, M., Reuss, D., Sick, V.: Two-point spatial velocity correlations in the near-wall region of a reciprocating internal combustion engine. In: SAE Technical Paper Series, SAE Technical Paper Series. SAE International400 Commonwealth Drive, Warrendale, PA, USA (2017). https://doi.org/10.4271/2017-01-0613

Peterson, B., Baum, E., Böhm, B., Dreizler, A.: Early flame propagation in a spark-ignition engine measured with quasi 4D-diagnostics. Proc. Combust. Inst. 35(3), 3829-3837 (2015). https://doi. org/10.1016/j.proci.2014.05.131

Peterson, B., Reuss, D.L., Sick, V.: On the ignition and flame development in a spray-guided directinjection spark-ignition engine. Combust. Flame 161(1), 240-255 (2014). https://doi.org/10.1016/j. combustflame.2013.08.019

Peterson, B., Baum, E., Dreizler, A., Böhm, B.: An experimental study of the detailed flame transport in a SI engine using simultaneous dual-plane OH-LIF and stereoscopic PIV. Combust. Flame 202, 16-32 (2019). https://doi.org/10.1016/j.combustflame.2018.12.024

Pierce, P.H., Ghandhi, J.B., Martin, J.K.: Near-wall velocity characteristics in valved and ported motored engines. In: SAE Technical Paper Series, SAE Technical Paper Series. SAE International400 Commonwealth Drive, Warrendale, PA, USA (1992). https://doi.org/10.4271/920152

Rakopoulos, C.D., Kosmadakis, G.M., Pariotis, E.G.: Critical evaluation of current heat transfer models used in CFD in-cylinder engine simulations and establishment of a comprehensive wallfunction formulation. Appl. Energy 87(5), 1612-1630 (2010). https://doi.org/10.1016/j.apene rgy.2009.09.029

Renaud, A., Ding, C.P., Jakirlic, S., Dreizler, A., Böhm, B.: Experimental characterization of the velocity boundary layer in a motored IC engine. Int. J. Heat Fluid Flow 71, 366-377 (2018). https://doi. org/10.1016/j.ijheatfluidflow.2018.04.014

Rutland, C.J.: Large-eddy simulations for internal combustion engines-a review. Int. J. Eng. Res. 12(5), 421-451 (2011). https://doi.org/10.1177/1468087411407248 
Schlichting, H., Gersten, K.: Boundary-Layer Theory. Springer, Berlin (2017). https://doi. org/10.1007/978-3-662-52919-5

Schmitt, M., Frouzakis, C.E., Wright, Y.M., Tomboulides, A., Boulouchos, K.: Direct numerical simulation of the compression stroke under engine relevant conditions: local wall heat flux distribution. Int. J. Heat Mass Transf. 92, 718-731 (2016). https://doi.org/10.1016/j.ijheatmasstrans fer.2015.08.074

Shimura, M., Yoshida, S., Osawa, K., Minamoto, Y., Yokomori, T., Iwamoto, K., Tanahashi, M., Kosaka, H.: Micro particle image velocimetry investigation of near-wall behaviors of tumble enhanced flow in an internal combustion engine. Int. J. Eng. Res. 20(7), 718-725 (2019). https:// doi.org/10.1177/1468087418774710

Stanislas, M., Okamoto, K., Kähler, C.J., Westerweel, J.: Main results of the second international PIV challenge. Exp. Fluids 39(2), 170-191 (2005). https://doi.org/10.1007/s00348-005-0951-2

Tropea, C., Foss, J.F., Yarin, A.L.: Springer Handbook of Experimental Fluid Mechanics. Springer, Berlin (2007). https://doi.org/10.1007/978-3-540-30299-5

Welch, C., Schmidt, M., Keskinen, K. Giannakopoulos, G., Boulouchos, K., Dreizler, A., Böhm, B.: The effects of intake pressure on in-cylinder gas velocities in an optically accessible single-cylinder research engine: submitted, not published. In: SAE Technical Paper Series, SAE Technical Paper Series. SAE International400 Commonwealth Drive, Warrendale, PA, USA (2020)

Zentgraf, F., Baum, E., Böhm, B., Dreizler, A., Peterson, B.: On the turbulent flow in piston engines: coupling of statistical theory quantities and instantaneous turbulence. Phys. Fluids 28(4), 045108 (2016). https://doi.org/10.1063/1.4945785 